RESTORING DISTURBED LANDSCAPES 


\title{
The Science and Practice of Ecological Restoration
}

\author{
Editorial Board \\ James Aronson, EDITOR \\ Karen D. Holl, ASSOciate EdiTor
}

Donald A. Falk, Richard J. Hobbs, Margaret A. Palmer

Wildlife Restoration: Techniques for Habitat Analysis and Animal Monitoring, by Michael L. Morrison

Ecological Restoration of Southwestern Ponderosa Pine Forests, edited by Peter Friederici, Ecological Restoration

Institute at Northern Arizona University

Ex Situ Plant Conservation: Supporting Species Survival in the Wild, edited by Edward O. Guerrant Jr., Kayri Havens, and Mike Maunder

Great Basin Riparian Ecosystems: Ecology, Management, and Restoration, edited by Jeanne C. Chambers and Jerry R. Miller

Assembly Rules and Restoration Ecology: Bridging the Gap

Between Theory and Practice, edited by Vicky M. Temperton, Richard J. Hobbs, Tim Nuttle, and Stefan Halle

The Tallgrass Restoration Handbook: For Prairies, Savannas, and Woodlands, edited by Stephen Packard and Cornelia F. Mutel

The Historical Ecology Handbook: A Restorationist's Guide to Reference Ecosystems, edited by Dave Egan and Evelyn A. Howell

Foundations of Restoration Ecology, edited by Donald A. Falk, Margaret A. Palmer, and Joy B. Zedler

Restoring the Pacific Northwest: The Art and Science of Ecological Restoration in Cascadia, edited by Dean Apostol and Marcia Sinclair

A Guide for Desert and Dryland Restoration:

New Hope for Arid Lands, by David A. Bainbridge

Restoring Natural Capital: Science, Business, and Practice, edited by James Aronson, Suzanne J. Milton, and James N. Blignaut

Old Fields: Dynamics and Restoration of Abandoned Farmland, edited by Viki A. Cramer and Richard J. Hobbs

Ecological Restoration: Principles, Values, and Structure of an Emerging Profession, by Andre F. Clewell and James Aronson 
River Futures: An Integrative Scientific Approach to River Repair, edited by Gary J. Brierley and Kirstie A. Fryirs

Large-Scale Ecosystem Restoration: Five Case Studies from the United States, edited by Mary Doyle and Cynthia A. Drew

New Models for Ecosystem Dynamics and Restoration, edited by Richard J. Hobbs, and Katharine N. Suding

Cork Oak Woodlands in Transition: Ecology, Adaptive Management, and Restoration of an Ancient Mediterranean Ecosystem, edited by James Aronson, João S. Pereira, and Juli G. Pausas

Restoring Wildlife: Ecological Concepts and Practical Applications, by Michael L. Morrison

Restoring Ecological Health to Your Land, by Steven I. Apfelbaum and Alan W. Haney

Restoring Disturbed Landscapes: Putting Principles into Practice, by David J. Tongway and John A. Ludwig

\section{SOCIETY FOR ECOLOGICAL RESTORATION INTERNATIONAL}

The Society for Ecological Restoration (SER) is an international nonprofit organization whose mission is to promote ecological restoration as a means to sustaining the diversity of life on Earth and reestablishing an ecologically healthy relationship between nature and culture. Since its foundation in 1988, SER has been promoting the science and practice of ecological restoration around the world through its publications, conferences, and chapters.

SER is a rapidly growing community of restoration ecologists and ecological restoration practitioners dedicated to developing science-based restoration practices around the globe. With members in more than 48 countries and all 50 U.S. states, SER is the world's leading restoration organization. If you wish to become a member, contact SER at 285 W. 18th Street, \#1, Tucson, AZ 85701. Tel. (520) 622-5485, e-mail: info@ser.org.www.ser.org.

The opinions expressed in this book are those of the authors and are not necessarily those of SER. 



\section{Restoring}

Disturbed

Landscapes

Putting Principles into Practice

David J. Tongway and John A. Ludwig 
Copyright (C) 2011 David J. Tongway and John A. Ludwig

All rights reserved under International and Pan-American Copyright Conventions. No part of this book may be reproduced in any form or by any means without permission in writing from the publisher: Island Press, 1718 Connecticut Avenue NW, Suite 300, Washington, DC 20009

Island Press is a trademark of The Center for Resource Economics.

\section{Library of Congress Cataloging-in-Publication Data}

Tongway, David J. (David John)

Restoring disturbed landscapes : putting principles into practice / David J. Tongway and John A. Ludwig.

p. cm. - (The science and practice of ecological restoration)

Includes bibliographical references and index.

ISBN-13: 978-1-59726-580-5 (cloth : alk. paper)

ISBN-10: 1-59726-580-2 (cloth : alk. paper)

ISBN-13: 978-1-59726-581-2 (pbk. : alk. paper)

ISBN-10: 1-59726-581-0 (pbk. : alk. paper) 1. Restoration ecology. 2. Landscape protection. 3. Landscape ecology. I. Ludwig, John A. II. Title.

QH541.15.R45T66 2010

$639.9-\mathrm{dc} 22$

2010013877

Printed on recycled, acid-free paper

Manufactured in the United States of America

109876654321

The information in this book is accurate to the best of the authors' knowledge. However, neither Island Press nor the authors are responsible for injuries that may occur as a result of the restoration procedures or activities described in this book.

Keywords: disturbed landscape, functional landscape, dysfunctional landscape, restoration, landscape restoration, restoration practitioner, landscape function analysis, landscape ecology, ecological restoration, open-cut coal mining, mine-site tailings storage, mine-site wasterock dump, road verge restoration, tree belt, water ponding, soil-surface indicator, adaptive management, monitoring indicator 


To our wives, Helen Tongway and Rosalind Ludwig, who encouraged us in so many, many ways to write this book. 

A complex system that works is invariably found to have evolved from a simple system that works.

John Gall 

FOREWORD James Aronson $\quad$ XV

PREFACE $\quad x i x$

ACKNOWLEDGMENTS X Xxi

PART I A Function-Based Approach to Restoring Disturbed Landscapes 1

Chapter 1 Our Approach to Restoring Disturbed Landscapes: Five-Step Adaptive Procedure 3

Chapter 2 A Framework for How Landscapes Function 7

Chapter 3 Principles for Restoring Landscape Functionality 19

PART II Case Studies on Restoring Landscapes: Mine Sites and Rangelands 27

Chapter 4 Restoring Mined Landscapes 29

Chapter 5 Restoring Damaged Rangelands 45

PART III Scenarios for Restoring Landscapes: Mine Sites, Rangelands, Farmlands, and Roadsides 63

Chapter 6 Restoration of Mine-Site Waste-Rock Dumps 65

Chapter 7 Restoration of Mine-Site Tailings Storage Facilities 75

Chapter 8 Restoring Landscapes after Open-Cut Coal Mining 87

Chapter 9 Restoring Rangelands with an Overabundance of Shrubs 97

Chapter 10 Renewing Pastureland Functions Using Tree Belts 107

Chapter 11 Restoration of Former Farmlands near $\begin{array}{ll}\text { Urban Developments } & 117\end{array}$

Chapter 12 Restoring Verges after Road Construction 129 
PART IV Monitoring Indicators

Chapter 13 Landscape Function Analysis: An Overview and Landscape Organization Indicators

Chapter 14 Landscape Function Analysis: Soil-Surface Indicators

Chapter 15 Ephemeral Drainage-Line Assessments: Indicators of Stability

Chapter 16 Vegetation Assessments: Structure and Habitat Complexity Indicators

Chapter 17 Reflections on Restoring Landscapes:

A Function-Based Adaptive Approach

REFERENCES

167

GLOSSARY 
Building on thirty-five years of collaborative reflection and observation, plus a vast amount of fieldwork and teaching, David Tongway and John Ludwig have written a marvelous book summing up their intertwined and complementary stocks of knowledge and experience in the science and practice of ecological restoration. This renowned duo have devoted their professional lives to understanding how natural landscapes work as biophysical systems, and how they are damaged by disturbances of various kinds. The assumption - borne out by much testing in the field - is that ecosystem rehabilitation and restoration strategies to some specified goal can become a much more assured process when based on the principles identified in the functional analysis of landscapes, and when applying a rational, stepwise approach, with regular reference to a specific, well-studied situation.

The approach and procedures provided here will help you learn not only how to "read" almost any terrestrial landscape, in a detailed but highly practical way, but also how to use that skill set for purposes of designing workable solutions to repair damage for your specific case, without getting locked into trying to apply restoration "recipes" or off-the-shelf approaches that very likely may not work. As the authors remind us, "you can't fix something unless you know how it works" (part 1). Focusing on biophysical realities at the landscape scale, Restoring Disturbed Landscapes presents a readily transferable approach and illustrates how restoration practitioners can reverse declines in the flow of goods and services supplied by landscapes of all kinds, provided they have studied how the systems work in the first place.

What the authors present, in a lucid, fluid, and accessible style, supported by ample illustrations and examples from their own experience, is their widely tested five-step procedure - setting clear goals; defining the problem; designing solutions; applying technologies and monitoring their effects; and, finally, as needed, adaptively improving technologies. Although first developed in arid and semiarid lands in Australia, Tongway and Ludwig's procedure and the underlying conceptual model, which the reader will find in chapter 2 , is applicable in high rainfall areas as well. This model provides the framework for the five-step procedure that has been tested by the authors in dozens of difficult sites and imparted to dozens of student and trainee groups around the world. 
I am convinced that for those practitioners who discover these authors for the first time, as well as for all those who have had the good fortune to participate in Dave Tongway's training sessions in landscape function analysis procedures, this book will be invaluable. It makes available the sound scientific underpinnings of landscape function analysis, stated in a manner that laypeople and students can follow. The authors wrote to me recently that "having observed a lot of poor rehabilitation and ineffective monitoring, we wanted to provide a synthesis of the needs for both activities, but not in a site-specific manner. This is where our articulation of the principles is so potentially useful to folk who want to do a good job, but only have intuition and rumors to work with. We want to open up all the science needed for restoration, but in an uncomplicated way. Few ordinary folk will have had the opportunity of reading the scientific literature as broadly as we have, so the book is to show that science is useful at the grassroots level of application."

This book will be of great interest to, and use for, teachers, students, volunteer and professional restoration practitioners, and, indeed, a wide range of scientists more or less closely engaged with restoration, as well. As anyone familiar with arid and semiarid land ecology, in particular, will recognize, the late, eminent ecologist Immanuel Noy-Meir was a strong influence on Dave and John, by drawing their attention to the need for heterogeneity of water distribution in semiarid and arid landscapes. A finer pedigree than that, one could hardly ask for. And Noy-Meir himself enthusiastically acknowledged what an important contribution the team of John Ludwig and David Tongway has made to applied ecology.

A word about The Science and Practice of Ecological Restoration Series: since the first volume appeared in 2002, this series has sought to embrace and, indeed, illuminate the entire breadth of the rapidly evolving field of ecological restoration, including all the different sciences and all the different forms of practice. The range of books nicely reflects SER and Island Press's shared mission vis-à-vis an ever-wider public concerned with conservation, sustainable use of resources, sustainability in general, and ecological restoration. However, there is certainly a need for more books that primarily address practitioners - and beginning students. This fine work by Tongway and Ludwig, which is the twentieth volume to appear in the series, goes a long way to rectify the balance, and it has the great virtue of being written by people who bridge the divide between scientists and practitioners. The scientific credentials and underpinnings of Tongway and Ludwig are as impeccable as their field experience - which is a(nother) rare and valuable asset, although it is a hallmark of this series that many of the contributing authors help make this vital bridge between science and effective practice. That way lies sustainability and restoration not only of landscapes but also of societies, cultures, and a global community looking for new models and alternative futures.

Global society urgently needs to change the way we do many things if we wish for a sustainable and desirable future. We need to control population growth; heavily tax stock market speculators; remove perverse subsidies wherever they persist; reduce ridiculous consumption patterns among the affluent and the very afflu- 
ent; and deeply respect the rights of all cultures, all species, and future generations of people. In light of the sorry state of our environment and ecosystems, and our overall relationship with the natural world, we also need to start investing much more heavily in the science, practice, and teaching of ecological restoration.

"Being able to 'read the landscape' is a rare and valuable asset." Those are the last words of this book you are about to read, and it won't spoil anything to quote them here. If you want to become more effective in restoring the functional capacity of disturbed landscapes and damaged ecosystems around the globe, you need to learn how to read landscapes, so please read and ponder this valuable and muchawaited book. Then, if you agree it is useful, share it with other people looking for insight and inspiration from two of the most experienced restoration scientists/practitioners anywhere.

James Aronson, editor The Science and Practice of Restoration Ecology Series 

In our changing world, human populations are rapidly growing and demanding more of the goods and services provided by landscapes. Restoration practitioners are needed who can improve the capacity of damaged landscapes to carry on these functions. Our aim in writing this book is to provide these practitioners with an approach to restoring the functional capacity of landscapes. Our function-based approach centers on a five-step, adaptive landscape restoration procedure, which we have found effective in restoring the functional capacity of disturbed landscapes in a wide variety of environments around the globe. This approach builds on a solid foundation of ecological concepts and principles, which can readily be put into practice.

The level of functional improvement aimed for depends on the goals of stakeholders - those people with an interest in, or dependence on, a landscape, whether or not they live in that landscape. Stakeholders may wish to restore a landscape to a more natural state to achieve improved biodiversity goals, for example, and this book can help practitioners work with stakeholders to achieve such goals.

However, Restoring Disturbed Landscapes is not about returning damaged lands to some notional "pristine" state; it is about repairing landscapes to an acceptable level of functionality. Unfortunately, the terms landscape renewal, reclamation, and rehabilitation are frequently used to imply that a pristine state is aimed for, especially in cases where the goal is to restore habitats for specific fauna. In this book we use such terms in the broader sense of repairing landscapes, damaged by various land uses, to an agreed state, rather than the narrow definition of restoring lands to some notionally prior state.

At the heart of Restoring Disturbed Landscapes is the five-step procedure of setting clear goals, defining the problem, designing solutions, applying technologies, and monitoring their effects, and, if needed, adaptively improving technologies. We will explain the principles behind this adaptive landscape restoration procedure and present examples to demonstrate why we believe that putting these principles into practice leads to successful landscape restoration.

Restoring Disturbed Landscapes will be of interest to restoration practitioners, such as natural resource managers, mine-site rehab professionals, elected lead- 
ers responsible for public lands, scientists, educators training their students, and members of the public caring for their lands. We feel that these dedicated people need easy-to-understand information that explains how to put basic principles into practice to facilitate the attainment of their landscape-restoration goals. This need was confirmed by practitioners who participated in workshops held around Australia and who contributed to the report "Restoring landscapes with confidence" (Lovett et al. 2008). Our aim is to meet this need and to encourage practitioners to think broadly and critically about their restoration problems, so that they can achieve their goals with as few "wrong turns" as possible.

David J. Tongway John A. Ludwig June 2010 
We are indebted to our many colleagues from Australia's Commonwealth Scientific and Industrial Research Organisation (CSIRO) for helping us form, test, and solidify the concepts and principles described in this book, and in particular to Brian Walker who, as a former chief of our CSIRO Division, cut us enough slack to explore and develop ideas as an unplanned output of our research. The foundation for our conceptual framework on how landscapes function is based on the pulse-and-reserve framework for arid and semiarid systems presented in the 1980s in papers by Brian Walker, Professor Mark Westoby, and the late, eminent desert ecologist Immanuel Noy-Meir.

We acknowledge with affection and appreciation the mentoring role, to both of us, of Walt Whitford, who as a friend and ecologist at New Mexico State University opened our eyes to the breadth of biotic and abiotic interactions in landscapes.

We thank the many practitioners who provided us valuable feedback on ways to clearly communicate concepts and principles in landscape ecology. We also thank Elizabeth (Ludwig) Tomko of Tomko Design for suggesting possible front cover designs, Yvette Salt for designing figure 1.1 (chapter 1), and all those who contributed images to this book (as acknowledged in the figure captions) where our own collections were insufficient.

We are indebted to the Society of Ecological Restoration (SER) for accepting this book into their series of distinguished Island Press publications. In particular we appreciate the enthusiastic support of James Aronson from the earliest stages of our book proposal to reviewing early drafts and writing a foreword. Previous SER/Island Press titles edited by Aronson and Andre Clewell were valuable guides in providing definitions we have adopted as standards. We especially value the professionalism of Island Press editors Barbara Dean, Erin Johnson, and Sharis Simonian, whose prompt responses helped us maintain our writing momentum and greatly improved our book.

David J. Tongway John A. Ludwig 